\title{
Reducing chronic obstructive pulmonary disease mortality in Korea: early diagnosis matters
}

Yong Il Hwang ${ }^{1,2}$

\author{
${ }^{1}$ Division of Pulmonary, Allergy \\ and Critical Care Medicine, \\ Department of Internal Medicine, \\ Hallym University Sacred Heart \\ Hospital, Anyang; ${ }^{2}$ Lung Research \\ Institute of Hallym University \\ College of Medicine, Anyang, \\ Korea
}

\section{See Article on Page 1272-1278}

The prevalence of chronic obstructive pulmonary disease (COPD) in Korea between 2007 and 2015 was about $13 \%$ [1] and the total economic costs attributable to COPD were estimated to be approximately 1,245 million USD $(1,408$ billion KRW) in 2013 [2]. COPD was the third leading cause of death in 2016 worldwide, claiming 3 million lives [3], and ranked 8th in causes of death in Korea in 2018 [4]. However, there have been no Korean studies of mortality rate or causes of death in patients with COPD.

In the current issue of the Korean Journal of Internal Medicine, Park et al. [5], using the National Health Insurance Service-National Sample Cohort (NHISNSC) database, report the 5 -year mortality rate of newly diagnosed COPD to be $25.4 \%$, and the most common cause of death to be chronic lower respiratory disease. This study makes us reconsider the situation of under-diagnosis and under-treatment of COPD, and provides new data on COPD mortality.

The 5-year mortality rate reported in that study differs from that of previous studies. The Lung Health Study (LHS), which enrolled patients with milder COPD, reported a 5-year mortality rate of $2.5 \%$ [6]. The 3-year mortality rates reported from the Towards a Revolu- tion in COPD Health (TORCH) study were $13 \%$ to $16 \%$, depending on the severity of air-flow limitation [7]. In a Danish population-based cohort study, the 3-year mortality rate was $10.0 \%$ in GOLD A and $36.9 \%$ in GOLD D [8]. This difference may reflect the fact that Korean COPD patients have more severe disease. It is well known that respiratory failure becomes the predominant cause of death in more advanced COPD patients [9]. This study also showed that only $1.5 \%$ of subjects were treated for COPD during the 12-year follow-up period. These results reflect a current situation of under-diagnosis and under-treatment of COPD in Korea.

In addition, the proportion of male patients in this study was lower than that of other cohort or epidemiological studies in Korea $[10,11]$. As the prevalence of COPD is higher than that of the general population among male ever-smokers [12], the issue of under-diagnosis and under-treatment of COPD is more severe for male patients.

As there is currently no medical treatment to reduce mortality from COPD [13], early detection and introduction of smoking cessation and COPD education could be an initial step to improve survival in patients with COPD [14]. The Korean Academy of Tuberculosis and Respiratory Diseases has developed Korean COPD guidelines [13], and has distributed various educational materials 
to improve the diagnosis and treatment of COPD. Additionally, a quality assessment program of COPD management has been conducted since 2014 by the Health Insurance Review and Assessment (HIRA) Service, to improve the quality COPD management [15]. Unfortunately, rates of diagnosis, treatment, and awareness of COPD are still very low $[1,15]$, despite these efforts. Therefore, many COPD patients in Korea are not receiving adequate treatment.

COPD is now considered to be caused not only by exposure to smoking or air pollution in adult life but also by poor lung growth as a result of malnutrition, infections, and/or passive exposure to pollutants [16]. For this reason, the role of government is important to address the current situation $[16,17]$. For example, a national, active care-finding strategy for subjects at high risk for COPD is one potential approach for government to consider, as with the National Lung Cancer Screening Program [18]. It should be kept in mind that COPD is a preventable and treatable disease [13].

\section{Conflict of interest}

No potential conflict of interest relevant to this article was reported.

\section{REFERENCES}

1. Hwang YI, Park YB, Yoo KH. Recent trends in the prevalence of chronic obstructive pulmonary disease in Korea. Tuberc Respir Dis (Seoul) 2017;80:226-229.

2. Kim C, Kim Y, Yang DW, et al. Direct and indirect costs of chronic obstructive pulmonary disease in Korea. Tuberc Respir Dis (Seoul) 2019;82:27-34.

3. World Health Organization. Top 10 cause of death 2016 [Internet]. Geneva (CH): World Health Organization, c2018 [cited 2019 Oct 8]. Available from: http://www.who.int/gho/ mortality_burden_disease/causes_death/top_10/en/.

4. Statistics Korea. Annual report on the causes of death statistics, 2018 [Internet]. Daejeon (KR): Statistics Korea, c1996 [cited 2019 Oct 8]. Available from: http://kostat. go.kr/portal/korea/index.action.

5. Park SC, Kim DW, Park EC, et al. Mortality of patients with chronic obstructive pulmonary disease: a nationwide population-based cohort study. Korean J Intern Med 2019;34:1272-1278.
6. Anthonisen NR, Connett JE, Enright PL, Manfreda J; Lung Health Study Research Group. Hospitalizations and mortality in the lung health study. Am J Respir Crit Care Med 2002;166:333-339.

7. Calverley PM, Anderson JA, Celli B, et al. Salmeterol and fluticasone propionate and survival in chronic obstructive pulmonary disease. N Engl J Med 2007;356:775-789.

8. Gedebjerg A, Szepligeti SK, Wackerhausen LH, et al. Prediction of mortality in patients with chronic obstructive pulmonary disease with the new Global Initiative for Chronic Obstructive Lung Disease 2017 classification: a cohort study. Lancet Respir Med 2018;6:204-212.

9. Sin DD, Anthonisen NR, Soriano JB, Agusti AG. Mortality in COPD: role of comorbidities. Eur Respir J 2006;28:1245-1257.

10. Hwang YI, Lee SH, Yoo JH, et al. History of pneumonia is a strong risk factor for chronic obstructive pulmonary disease (COPD) exacerbation in South Korea: the Epidemiologic review and Prospective Observation of COPD and Health in Korea (EPOCH) study. J Thorac Dis 2015;7:2203-2213.

11. Lee JY, Chon GR, Rhee CK, et al. Characteristics of patients with chronic obstructive pulmonary disease at the first visit to a pulmonary medical center in Korea: the KOrea COpd Subgroup Study Team Cohort. J Korean Med Sci 2016;31:553-560.

12. Hwang YI, Park YB, Yoon HK, et al. Male current smokers have low awareness and optimistic bias about COPD: field survey results about COPD in Korea. Int J Chron Obstruct Pulmon Dis 2019;14:271-277.

13. Park YB, Rhee CK, Yoon HK, et al. Revised (2018) COPD clinical practice guideline of the Korean Academy of Tuberculosis and Respiratory Disease: a summary. Tuberc Respir Dis (Seoul) 2018;81:261-273.

14. Lee JY, Rhee CK, Jung KS, Yoo KH. Strategies for management of the early chronic obstructive lung disease. Tuberc Respir Dis (Seoul) 2016;79:121-126.

15. Chung SM, Lee SY. Evaluation of appropriate management of chronic obstructive pulmonary disease in Korea: based on Health Insurance Review and Assessment Service (HIRA) claims. Tuberc Respir Dis (Seoul) 2017;80:241246.

16. Halpin DMG, Celli BR, Criner GJ, et al. It is time for the world to take COPD seriously: a statement from the GOLD board of directors. Eur Respir J 2019;54:1900914.

17. National Heart, Lung, and Blood Institute. COPD Na- 
tional Action plan [Internet]. Bethesda (MD): National Heart, Lung, and Blood Institute, 2019 [cited 2019 Oct 8]. Available from: https://www.nhlbi.nih.gov/health-topics/ education-and-awareness/COPD-national-action-plan.
18. National Cancer Center. National Cancer Screening Program [Internet]. Goyang (KR): National Cancer Center, 2019 [cited 2019 Oct 8]. Available from: https://www.ncc. re.kr/main.ncc?uri=manageo1_4. 